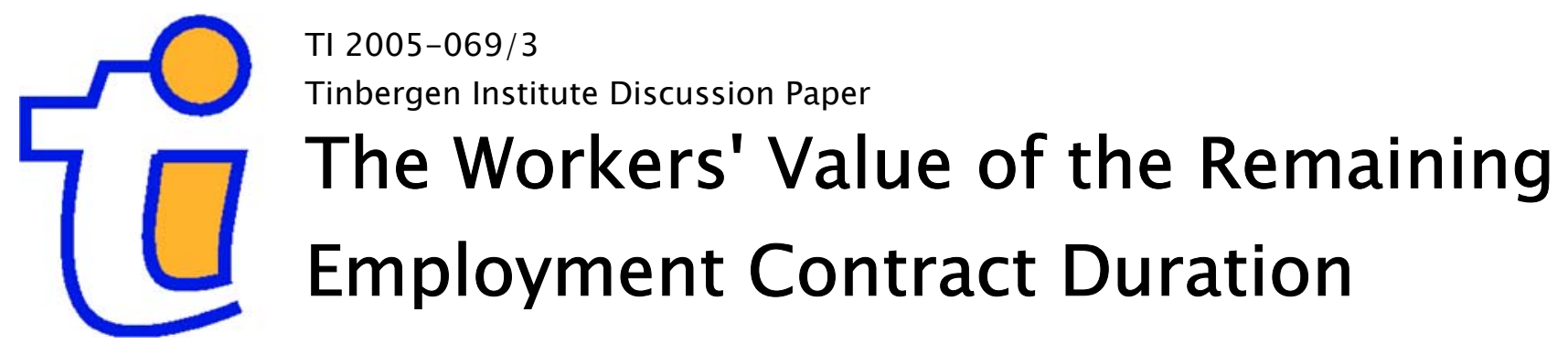

Jos Van Ommeren'

Mihails Hazans²

' Free University, Amsterdam, The Netherlands;

2 University of Latvia, Riga, Latvia. 


\section{Tinbergen Institute}

The Tinbergen Institute is the institute for economic research of the Erasmus Universiteit Rotterdam, Universiteit van Amsterdam, and Vrije Universiteit Amsterdam.

Tinbergen Institute Amsterdam

Roetersstraat 31

1018 WB Amsterdam

The Netherlands

Tel.: $\quad+31(0) 205513500$

Fax: $\quad+31(0) 205513555$

Tinbergen Institute Rotterdam

Burg. Oudlaan 50

3062 PA Rotterdam

The Netherlands

Tel.: $\quad+31(0) 104088900$

Fax: $\quad+31(0) 104089031$

Please send questions and/or remarks of nonscientific nature to driessen@tinbergen.nl.

Most TI discussion papers can be downloaded at http://www.tinbergen.nl. 


\title{
The workers' value of the remaining employment contract duration
}

\author{
Jos Van Ommeren* \\ Free University, Amsterdam, The Netherlands \\ Mihails Hazans** \\ University of Latvia, Riga, Latvia
}

$16 / 06 / 2005$

*Free University, FEWEB, De Boelelaan, 1081 HV Amsterdam, the Netherlands; Email: jommeren@ feweb.vu.nl Jos van Ommeren is affiliated to the Tinbergen Institute, Amsterdam, the Netherlands.

** Mihails Hazans is a fellow of Baltic International Centre for Economic Policy Studies (BICEPS). Hospitality of Centre for European Integration Studies (ZEI) at University of Bonn gratefully acknowledged. Email:

mihazan@lanet.lv. We would like to thank Marcel Hoogzaad for research assistance. 


\section{The workers' value of the remaining employment contract duration}

Abstract. This paper introduces and applies a method for estimating workers' marginal willingness to pay for job attributes employing data on job search activity. Worker's willingness to pay for the remaining duration of the employment contract is derived. We provide evidence that workers attach substantial value to the remaining contract duration. A temporary worker with a remaining contract of 6 months is willing to pay about $10 \%$ of the wage to increase the contract by one month.

Keywords: On-the-job search; Job attributes; Contract duration; Temporary job.

JEL: J3, J6.

\section{INTRODUCTION}

Since the eighteenth century, when Adam Smith wrote "The Wealth of Nations", economists have been interested in how the theory of compensating wage differentials might explain the existence of wage differences in the labour market. One of the attractions of this theory is that it allows for the estimation of workers' marginal willingness to pay (MWP) for job attributes such as collective bargaining and the risk of becoming unemployed. This may explain the impressive number of empirical hedonic wage studies that have focused on the workers' willingness to pay for attributes. Although many studies have shown that nonwage differences between jobs can be significant to workers, the general conclusion is that nonwage differences between jobs are not 
very important to workers (see Brown, 1980; Rosen, 1986).

The theory of compensating wage differentials assumes that workers have complete information in a static environment. This suggests that if job outcomes are a result of a dynamic process and workers having to search for jobs, estimates for the willingness to pay for job attributes may be biased. These considerations have encouraged theoretical research that looks at the willingness to pay for attributes. In particular, it has been demonstrated that the estimates of the conventional marginal willingness to pay for a job attribute are likely to be biased downwards if it is not acknowledged that a job is a search good and a result of a match between an employer and a worker (Hwang et al., 1992). For example, if firms differ with respect to the cost of providing nonwage job attributes, then low cost firms offer both higher wages and greater values of desirable job attributes, because they face greater opportunity costs in having job vacancies go unfilled. This example may be particularly relevant in the context of the risk of unemployment, because more profitable firms are less likely to make employees redundant.

Hwang et al. (1998) demonstrate that the estimate of the workers' MWP derived from the conventional hedonic wage methodology are biased when firms are heterogeneous and on-thejob mobility is present. This strongly suggests that MWP estimates are particularly biased for subgroups of workers / jobs for which on-the-job mobility is high. The main examples here are workers with a temporary contract.

These considerations have generated a number of studies aimed at estimating the MWP for job attributes using data on job moving behaviour and comparing the MWP estimates with conventional estimates (Herzog and Schlottmann, 1990; Gronberg and Reed, 1994; Van Ommeren et al., 2000; Manning, 2003). ${ }^{1}$ These studies point to considerably higher estimates

\footnotetext{
1 In addition, these considerations have generated a number of studies to improve conventional estimates by correcting for mobility bias (see, for example, Kim, 1992).
} 
than those based on conventional hedonic wage methods. Herzog and Schlottmann (1990) and Gronberg and Reed (1994) reported higher estimates for the willingness to pay to avoid jobinduced risk. Van Ommeren et al. (2000) and Manning (2003) found higher estimates for the willingness to pay to avoid commuting. Similarly, Bartik et al. (1992) compared the MWP for residential characteristics based on residential moving behaviour and hedonic price methods and showed that the MWP estimates for crime reduction and school quality are higher than those based on conventional estimates. In addition, McCue and Reed (1996) examined self-reported data on the workers' willingness to pay for job attributes, and concluded that "workers' valuations of nonpecuniary dimensions of work are substantially larger than previous research has indicated".

Given the frequent use of hedonic-based models to assess the benefits of environmental, health and safety regulations in the labour and housing market, these results are relevant for theoretical and applied research and policy makers. "Hedonic-based benefit estimates should be used with caution, and other benefit estimation approaches should receive greater emphasis." (Bartik et al., 1992). A substantial progress has been made recently in the methodology of estimating willingness to pay for various job attributes (see e. g. Heckman et al, 2003, Ekeland et al 2003). A rapidly growing literature addresses individual heterogeneity and selection bias (see e.g. Carneiro et al. 2003; Heckman and Li, 2003). However, this strand of literature relies on the equilibrium assumption that workers maximize their utility at the current job. We argue in the current paper that for certain applications, such as in the case of temporary jobs, such an assumption may be inaccurate.

In this paper, we use a method to estimate the MWP for job attributes that explicitly acknowledges that jobs are search goods. We demonstrate that the workers' MWP for job attributes can be derived from data on job search activity. This estimation method is based on the 
same type of theoretical search model as those studies in which MWP estimates are derived from data on job moving behaviour (Gronberg and Reed, 1994; Van Ommeren et al., 2000). In these search models, it is assumed that workers are involuntarily separated due to firm firings (e.g. Gronberg and Reed, 1994). We relax this assumption by assuming that the involuntarily separation rate may depend on job attributes. This extension is essential, because both Gronberg and Reed (1994) and Van Ommeren et al. (2000) explicitly assume that the involuntary separation rate is exogenous of job attributes. Gronberg and Reed (1994, p. 913) state "The assumption that the involuntary separation rate is exogenous of firm wage and nonwage characteristics is crucial for empirically identifying workers' marginal willingness to pay for job attributes." $^{2}$ The exogeneity assumption is clearly not innocuous and limits the applicability of the MWP method, since it implies that firms fire randomly disregarding the wage of the worker although it seems plausible that firms make the worker's wage part of the firing decision. Moreover, by allowing the involuntary separation rate to depend on job attributes, we are able to generate estimates of the MWP for job attributes such as the duration of the employment contract, which are related to the risk of becoming unemployed. ${ }^{3}$

In this paper, we estimate workers' marginal willingness to pay for job attributes in Estonia (1998-2001) and Lithuania (2000). Our emphasis is on the MWP for the remaining duration of the employment contract. An important distinction is therefore between permanent jobs (contracts of unlimited duration) and temporary jobs, (i.e. contracts of fixed duration and seasonal or casual jobs). Temporary jobs are associated with a higher than average unemployment risk: Table 1 shows that in 1999-2002 workers with fixed-term contracts in

\footnotetext{
${ }^{2}$ Khanker (1988) employs the identical exogeneity assumption in his work on compensating wage differentials.

${ }^{3}$ In the literature on the theory of compensating wage differentials there is a large interest in MWP estimates of the risk of becoming unemployed (Rosen, 1986). Compensating wage differentials estimation methods are plagued by the endogeneity of job riskiness (Garen, 1988; Moretti, 2000). As is well known, search theory is particularly well suited to the analysis of the effect of risk on labor market behaviour (Mortensen, 1986).
} 
Estonia and Lithuania were several times more likely to become unemployed or inactive one year later than workers with permanent contracts. ${ }^{4}$ Temporary contracts may have other disadvantages as well for workers. For example, there is evidence that temporary workers receive less on-the-job training (Booth et al., 2002). According to Estonian LFS 2001 data, 3.5 percent of permanent workers and none of the temporary workers participated in training courses or seminars at work during the 4 weeks before the survey. ${ }^{5}$ Estimates of MWP for temporary jobs therefore do not only measure the MWP for risk, but also for other unobserved job attributes. It is however plausible that the remaining duration of the job contract, conditional on the type of contract, is unrelated to unobserved job attributes such as training, so the MWP for remaining duration provides a more precise estimate of the MWP for unemployment risk.

Lithuania and Estonia are former Soviet republics, which at the time of observation were at the end of their first decade of transition to the market economy. Labour force participation in both countries was then close to the EU average, but the unemployment rate was high (16.1 percent according to ILO definition in Lithuania, 2000; 12.8 percent in Estonia, 2001). This, combined with subjective evidence, suggest that workers were concerned about the risk of losing their jobs. ${ }^{6}$ Other relevant job-security related features of Lithuanian and Estonian labour markets, which distinguish them from established market economies, are very low unionisation

\footnotetext{
${ }^{4}$ This is consistent with the late 1990s results for EU-15 reported by European Commission, 2002, Table 25. Similarly, in OECD countries perceived job security in late 1990s was lower for temporary workers (OECD 2004, Chart 2.8).

${ }^{5}$ Controlling for variety of worker and characteristics, temporary workers in EU-15 are significantly less likely to be satisfied with their jobs (European Commission, 2002, Table 31).

${ }^{6}$ Regular public opinion polls show that job security is the most important characteristic of work for workers in the Baltic countries. Rose (2000, p.12) reports that about $90 \%$ of employed respondents are worried about possibility of losing their job. The main explanation is plausibly the combination of high unemployment rates and low levels of unemployment and welfare benefits. Lithuania's unemployment benefits do not follow an insurance principle and are maximally two-third of the minimum wage and less than half of the average gross wage. Furhermore, most unemployed do not receive unemployment benefits (UB). In Estonia only about 25 percent of unemployed receives earnings-related UB, and about 50 percent receive unemployment assistance benefit (less than 10 percent of average monthly wages). Hence, the welfare loss from becoming unemployed is likely much larger for workers in Lithuania and Estonia than for EU-15 workers.
} 
(OECD, 2003) and little workers' preference towards shorter working hours or part-time work. ${ }^{7}$ Employment protection legislation related to contracts of unlimited duration in Estonia and Lithuiania is stricter than EU-15 average, while regulation of limited duration contracts is more liberal (see Eamets and Masso (2004)). Such legislation, as shown in OECD (2004) is likely to result in low job security for temporary workers.

The outline of the paper is as follows. In section two we introduce the search model. We then derive the optimal search strategy in section three and derive the workers' marginal willingness to pay for nonwage job attributes. In section four, the estimation method for the MWP is discussed. The MWP for the employment contract duration is estimated for Estonia and Lithuania in section five. Section six concludes the paper.

\section{THE SEARCH MODEL}

The point of departure in this paper is an employed individual who lives forever. This individual derives utility from job attributes $X . v(X)$ is the quasi-concave instantaneous utility function associated with a job having attributes $X$. Employed individuals take into account that they may become unemployed in the future. Let $\delta$ denote the involuntary separation rate of workers from jobs. We emphasise that $\delta$ may depend on job nonwage attributes $X$, so $\delta=\delta(X)$. In particular, the risk of becoming unemployed is a decreasing function of the remaining duration of the employment contract. We allow $\mathrm{X}$ to be non-stationary, so $\mathrm{X}$ may include the employment contract duration, which decreases over time. For simplicity, we assume that all job attributes $\mathrm{X}$ are stationary, except the remaining contract duration, denoted as $\tau$, which decreases over time. Hence, at $\tau=0$, the employed will become unemployed.

\footnotetext{
7 Just 7 percent of all employees in Lithuania would like to work shorter hours if their earnings are adjusted accordingly, while in EU-15 and Norway, this figure is, on average, 49 percent (EFILW, 2003).
} 
The employed person searches in the labour market with effort $s$ at a cost of $k(s), s \geq 0$. Search costs $k(s)$ are increasing and convex in search effort $s$, hence $k^{\prime}(s)>0$ and $k^{\prime \prime}(s)>0$. Jobs arrive with arrival rate $p(s)$. The job arrival rate $p$ is increasing and concave in $s$, hence $p^{\prime}(s)>0$ and $p^{\prime \prime}(s)<0$. We suppose that the effects of the search costs on instantaneous utility are additive. Job attributes offers are drawn randomly from a given distribution, which is independent of $X{ }^{8} X_{0}$ denotes the attributes of the job offered to the job searcher. Pooling of offers is not allowed: job offers are either refused or accepted before other offers arrive.

The expected lifetime utility received from the current job is denoted as $V(X)$. Future utility is discounted at rate $\rho$. $V$ includes the possibility of offers in the future. The individual is assumed to maximise lifetime utility $V$. The decision whether to accept a job offer accounts for expected future offers. Discounted lifetime utility can then be written as the sum of the instantaneous utility, the expected benefit of accepting a job offer during the next time unit and the expected loss of becoming unemployed. $U$ denotes the expected lifetime utility of an unemployed individual. This leads to the following equation:

$$
\rho V(X)=v(X)-k(s)+p(s) E \max \left[V\left(X_{0}\right)-V(X), 0\right]+\delta(X)[U-V(X)]-\frac{\partial V(X)}{\partial \tau}
$$

In this expression the expectation $\mathrm{E}$ is taken with respect to the distribution of the job attributes $\mathrm{X}_{0}$. The interpretation of the above formula is well known (see e.g. Mortensen, 1986). Current utility equals $\mathrm{v}(\mathrm{X})-\mathrm{k}(\mathrm{s})$. At rate $p(s)$ a job offer will be received, and that offer will be accepted if the value of the new job exceeds that of the current position. Hence, the optimal acceptance

\footnotetext{
${ }^{8}$ In case the employed individual considers taking a second job, the distribution of job attributes of both jobs depends on $\mathrm{X}$, so this assumption is violated. The proportion of workers that consider a second job is small. In the data we analyse later on, only $0.4 \%$ of all workers (4.3\% of all searchers) search for a second job.
} 
strategy is to accept a job offer if $V\left(X_{0}\right)-V(X)>0$. The offer should otherwise be rejected. At rate $\delta(\mathrm{X})$, the worker may become unemployed. The term $\partial \mathrm{V}(\mathrm{X}) / \partial \tau$ equals the depreciation in $\mathrm{V}$ as the contract is due to expire at $\tau=0$ (Van den Berg, 1990)

\section{THE MARGINAL WILLINGNESS TO PAY FOR JOB ATTRIBUTES}

In this section, the choice of search effort $s$ is derived using the first-order condition for the worker's optimal search effort. The optimal choice of $s$ is obtained by differentiating equation (1)

with respect to $s$, and setting the resultant to zero (and noting that $\partial^{2} \mathrm{~V}(\mathrm{X}) / \partial \tau \partial \mathrm{s}=0$ ) gives us:

$$
-\frac{\partial k}{\partial s}+\frac{\partial p}{\partial s} E \max \left[V\left(X_{0}\right)-V(X), 0\right]=0 \quad \text { if } s>0
$$

The interpretation of equation (2) is well known (Mortensen, 1986). The marginal search cost equals the marginal benefit of an increase in the job arrival rate. The second-order condition is that the left-hand side of equation (2) is decreasing in $s$. The concavity of $p$ and the convexity of $k$ in their arguments ensure that this condition will be satisfied. Our conditions do not ensure that job effort is positive. Hence, if $s=0$, then the marginal costs of search are higher than the marginal benefits and (2) does not hold.

We will use equation (2) to express the marginal effect of a change in a job attribute $X_{i}$ on the workers' search effort. Dividing both sides by $\partial p / \partial s$, differentiating with respect to $X_{i}$ and using the envelope theorem (so the effect of $\mathrm{X}_{\mathrm{i}}$ on $\mathrm{V}$ via $s$ can be ignored since $\partial V / \partial s=0$ ), gives:

$$
\frac{\partial s}{\partial X_{i}} \frac{\partial}{\partial s}\left[-\frac{\partial k}{\partial s} / \frac{\partial p}{\partial s}\right]-\operatorname{Pr}\left[V\left(X_{0}\right)-V(X)>0\right] \frac{\partial V(X)}{\partial X_{i}}=0, \quad \text { if } s>0
$$


where $\operatorname{Pr}\left[V\left(X_{0}\right)-V(X)>0\right]$ denotes the probability of accepting a job offer (note that $\left.\partial E \max \left[V\left(X_{0}\right)-V(X), 0\right] / \partial X_{i}=-\partial V(X) / \partial X_{i} . \operatorname{Pr}\left[V\left(X_{0}\right)-V(X)>0\right]\right)$. Suppose that $i=1, \ldots, \mathrm{n}+1$ and that the $n+1$ 's job attribute is the wage. The workers' marginal willingness to pay for the ith nonwage job attribute $\left(M W P_{i}\right)$ is here defined as the ratio of the marginal lifetime utility of the ith job attribute over the marginal lifetime utility of the wage, so $\mathrm{MWP}_{\mathrm{i}}=\left[\partial \mathrm{V}(\mathrm{X}) / \partial \mathrm{X}_{\mathrm{i}}\right] /[\partial \mathrm{V}(\mathrm{X}) / \partial \mathrm{w}]$. Hence, by using equation (3), we obtain:

$$
M W P_{i}=\frac{\partial s}{\partial X_{i}} / \frac{\partial s}{\partial w}, \quad \text { if } s>0
$$

where $i=1, \ldots, n$. Our main result is that the workers' marginal willingness to pay for the ith nonwage job attribute, $M W P_{i}$, equals the ratio of the marginal effects of the ith nonwage attribute and the wage on search effort. We emphasise here that these $M W P_{i}$ estimates are derived from the relationship between $\mathrm{X}_{\mathrm{i}}$ and job search behaviour. As emphasised in the introduction, MWP estimates based on observations of job moves need to rely on the assumption that $\delta$ does not depend on X (Gronberg and Reed, 1994). This assumption is needed, because job moves consist of voluntary and involuntary job moves, which are not distinguishable. ${ }^{9}$ In case of observations of job search, one does not need such an assumption, because job search is always voluntarily, even if triggered by a threat of involuntary separation.

\footnotetext{
${ }^{9}$ One of the consequences is that if involuntary moves are positively associated with wages (hence, employers are more likely to fire workers with higher wages), the MWP estimates based on job mobility are too high. This may be one of explanations why MWP estimates based on job mobility tend to be high. For example, in a recent application, the results by Manning (2003) based on the British Labor Force Surveys and Household Panel Surveys suggest that the MWP estimates for commuting time based on job mobility are too high. In these surveys, one cannot distinguish between voluntary and involuntary moves.
} 


\section{ESTIMATION METHOD}

We will discuss here a method for estimating workers' MWP for job attributes given information on search behaviour. Suppose that exact information on desired search effort $s$ is not available and it is only known whether workers report that they search $\left(s^{*}=1\right)$ or do not search $\left(s^{*}=0\right)$. Workers report that they search when search effort exceeds zero. One may then specify search activity $s^{*}$ by means of a latent-variable framework: $s=\beta^{\prime} Y+u, E(u)=0 ; \beta$ is a vector of unknown coefficients. $Y$ represents a vector of explanatory variables which includes job attributes $X ; u$ is a random variable with expectation 0 . So, $s$ and $s^{*}$ are related as follows: $s^{*}=1$, if $s>0$ and $s^{*}=0$ if $\mathrm{s} \leq 0$. Estimation of this discrete choice model is standard. Estimates of $\beta$ are consistent, because estimating a tobit specification using a probit model generates consistent (but inefficient) estimates of $\beta / \sigma$, where $\sigma$ is the standard deviation of the error term (Maddala, 1983, p. 159). We may ignore $\sigma^{-1,}$ because it cancels out when we calculate the MWP as we focus on the ratio of $\beta$ 's.

Let $\beta_{i}$ be the parameter associated with job attribute $X_{i}, i=1, \ldots, \mathrm{n}+1$. It is then obvious that $\partial E(s \mid s>0) / \partial X_{i}=\partial E(s) / \partial X_{i}=\beta_{i}, i=1, \ldots, \mathrm{n}+1$. So, although (4) only holds for $s>0$ (and not for $s=0$ ), it is sufficient to consistenly estimate $\beta_{i}$, and therefore $\mathrm{MWP}_{\mathrm{i}}$, using data on $s^{*}$. Suppose now that the $n+1$ 's job attribute is the logarithm of the wage and let $\beta_{w}$ be the parameter associated with the logarithm of the wage. The ratio of the marginal effects of the ith nonwage attribute and the wage on expected conditional search effort, the condition being that $s>0$, is then equal to $w \beta_{i} / \beta_{w}$ and thus using (4):

$$
M W P_{i}=w \beta_{i} / \beta_{w}, \quad i=1, \ldots, n .
$$


In consequence, estimates of $w \beta_{i} / \beta_{w}$ can be interpreted as the workers' marginal willingness to pay for the $i$ th nonwage job attribute $\left(M W P_{i}\right)$. Hence, the $M W P_{i}$ is proportional to the current wage. ${ }^{10}$

\section{EMPIRICAL APPLICATIONS}

\subsection{Data, descriptives and methods}

Our data come from several national labor force surveys. Our main results are based on 21075 observations of employees living and working in Estonia (in 2001) and on 2641 observations of employees living and working in Lithuania in 2000 (fourth quarter). For some descriptive variables, we will use data from other years as well to present similar figures for both countries.

Incidence of on-the-job search in Estonia is 4.2 percent, while in Lithuania it was 8.8 percent in $2000^{11}$ (but dropped to 4.5 percent in 2002-2003). Table 2 reveals that in both countries temporary workers, ${ }^{12}$ as well as part-time workers and those with short tenures are much more likely to search. Workers with short temporary contracts (less than 6 months) are more likely to be engaged in search than those with longer temporary contracts. The descriptives indicate that temporary and part-time males search more often than their female counterparts. Nevertheless, compared to data from West-European countries, observed search differences between males and females are relatively small. For example in the UK and in the Netherlands,

\footnotetext{
${ }^{10}$ It may be argued that the effect of $\mathrm{X}_{\mathrm{i}}$ on $s$ is structurally different for $s>0$ from the case that $s \leq 0$. This does not affect (5), because in this case $\partial E(s \mid s>0) / \partial X_{i}=\beta_{\mathrm{i}} \operatorname{Pr}(\mathrm{s}>0)$, so (5) follows again.

${ }^{11}$ Incidence of on-the-job search including search for a second job is only slightly higher $(9.2 \%)$. This percentage is comparable to EU countries. For example, the same percentage is reported in the Netherlands (Statistics Netherlands, 1992). In the UK, somewhat lower percentages are reported (Pissarides and Wadsworth, 1994).

${ }^{12}$ The average contract duration in Lithuania is just under 6 months. About $70 \%$ of the contracts are for less than 6 months. For Estonia, total contract duration is not reported, but average remaining duration is 3.5 months which implies average total duration of 7 months given random sampling. Hence, the average contract durations are almost identical.
} 
part-time female workers search on average less than their full-time counterparts (e.g. Pissarides and Wadsworth, 1994), whereas in Lithuania and Estonia they search more. ${ }^{13}$ This phenomenon is thought to be related to the strong employment position of females in the Baltic labor markets (OECD, 2003).

Subjective information indicates that in both countries 50 to $60 \%$ of the job searchers state that they search because they wish to improve their working conditions, about $20 \%$ search because the current job is anticipated to be terminated or seen as transitional and another $20 \%$ search to increase the number of the hours worked (see Table 3 ). ${ }^{14}$ Table 3 also suggests that the reasons for search are similar for males and females. ${ }^{15}$ As one might expect, most temporary workers search because the current job will be terminated or is seen as transitional.

\subsection{Results}

Our key variable of interest, the remaining duration of the contract, is observed directly for Estonia, but not for Lithuania and therefore the results will be presented separately. We will first discuss the results for Estonia.

\subsubsection{Estonia}

MWP estimates have been derived from a range of probit models ${ }^{16}$. The theoretical section suggests following specification of the search effort $s$ :

\footnotetext{
${ }^{13}$ In this sense, the Lithuanian and Estonian labor markets are more similar to the US labor market.

${ }^{14}$ Respondents were allowed to choose only one reason.

${ }^{15}$ The data suggest that part-time work is not seen as attractive in Lithuania and Estonia. Part-time workers tend to search in particular because they wish to increase the number of working hours.

16 Post-stratifying weights provided by the Statistical Department were used in the estimation process. Reported standard errors are the robust ones and allow for clustering within households. MWP estimates appear to be insensitive to the use of weights. Results without weights can be received from the authors upon request.
} 


$$
s=\beta^{\prime} Z+\beta_{\text {temp }} T E M P+\beta_{\text {dur }} \log (D U R) * T E M P+\beta_{w} \log (w)+u,
$$

where TEMP is a dummy for temporary jobs (as classified by the worker), DUR is the remaining contract duration in months, $Z$ is vector of other personal, job and background characteristics (to be discussed later), and $u$ is random error. The contract duration is specified in logarithms, which is consistent with the assumption that the utility function $v$ is plausibly a concave function of the contract duration. Given (4) and (6), MWP for an extra month of contract duration for a temporary worker is inversely related to duration:

$$
M W P_{d u r}=w \frac{\beta_{d u r} / \beta_{w}}{D U R}
$$

i.e. workers with short contracts are more concerned about their job security ${ }^{17}$. As control variables, we distinguish between three different types of permanent contracts which differ from the standard permanent contract. Workers employed as civil servants have permanent contracts which differ from other workers. Further, a small number of workers have 'verbal contracts' or 'contracts of agreement' which tend to give less protection than the standard permanent contract but for which the duration is not specified. Other control variables include worker's education, age (and its square), tenure, gender, belonging to ethnic minority, living in rural area, having non-manual occupation, as well as plant size and working in public or private sector. Furthermore, we control for sector of employment (15 industries) and region by residence (15 counties and capital city). The results estimates of (6) can be found in Table 4, specification [1]). It demonstrates that a temporary worker with a remaining 6 months contract is willing to pay 9.7 
(s.e. 5.1) percent of monthly wage for a one month extension. This implies that a worker with a new 6 months contract is willing to pay once 170 (s.e. 89) percent of monthly wage to get a 10 year contract. 1819

The above presented result ignores that it may be argued that very long temporary contracts are effectively as valuable as a permanent contract (in fact, it is more difficult to fire workers with temporary contracts which have not expired yet than those with permanent ones), suggesting that the estimate, although consistent, is not efficiently estimated. Therefore, we presume that a 120 months contract duration is as valuable to a worker as a permanent contract, and set $D U R$ equal to 120 for permanent jobs with 'regular' employment contracts, while the TEMP dummy is dropped from (6). ${ }^{20}$ This specification (not reported in the Tables) gives MWP for an extra month (evaluated at a 6 months remaining duration) equal to 10.5 (s.e. 1.8) percent of monthly wage. This estimate is close to the previous one but has a substantially smaller error. Note that the latter MWP estimate is more efficiently estimated, but the estimate may be inconsistent, because the added restriction may be invalid for arguments given above. Several tests do not reject this restriction however. ${ }^{21}$

The estimates may be criticised on the ground that the wage is reported with measurement error, resulting in a smaller $\beta_{w}$ and therefore an upward bias in the MWP. To

\footnotetext{
${ }^{17}$ There are two roughly equally sized groups of temporary workers in our sample: those with remaining contract duration up to 3 months and those with remaining duration from 3 months to 5 years.

${ }^{18}$ The latter result is derived by integrating (7) over the interval [6;120].

${ }^{19}$ Note further that the estimate for the temporary job dummy implies that the willingness to pay for a temporary job is equal to 303 (s.e. 42), which exceeds the derived willingness to pay based on the coefficient of the remaining duration. This makes sense, because the latter estimate measures only the risk of becoming unemployed, whereas the former includes the value of having a permanent contract that may offer also other fringe benefits (e.g. pensions) but also more training (see Booth et al., 2002).

${ }^{20}$ The model includes both dummies for workers with verbal contracts and contracts of agreement .

${ }^{21}$ Employing a Hausman t-test, the restriction was not rejected at the $10 \%$ level. Moreover, the results are hardly sensitive with respect to the choice of 120 months.
} 
address this issue, we have instrumented the wage using several instruments. ${ }^{22}$ The instruments used are (i) job location (16 regional dummies), (ii) whether Estonian is the worker's mother language, (iii) working in unionised firm, (iv) whether the worker was unemployed in the previous year, (v) whether the worker was not in the labour force in the previous year, and (vi) more detailed controls for occupation. ${ }^{23}$

We have experimented with a combination of several instrumental variables, but the results are similar. In line with the measurement error argument, the estimate for the wage is somewhat larger (in absolute value), but the estimates of the other explanatory variables, including the remaining contract duration, are essentially the same. The lowest MWP for an extra month among a range of specifications is equal to 6.3 (s.e. 3.5). Application of a Hausman-test does not reject the standard probit estimate at the $10 \%$ level for any of the estimates. The overall conclusion is therefore that measurement error of the wage may have a minor downward influence on the reported results in Table 4, but the downward bias is too small to detect with the given data.

The remaining contract duration may be endogenous if the total contract duration is endogenous. It may be argued that the total contract duration, the sum of the elapsed and remaining contract duration, is endogenous with respect to the job search choice. For example,

\footnotetext{
${ }^{22}$ In this way, we also address the issue that the wage is endogenously determined, although in search models this is usually not considered an issue of large concern.

${ }^{23} \mathrm{We}$ emphasize here that in the job search model, residence location is included as control variables. The main assumption is that the workplace location affects the wage, in line with a large empirical literature, whereas the job search activity takes place from the residence location. It is clear that Estonian language skills are related to productivity and therefore affect the wage. There is no good reason why Estonian language skills directly affect search activity (we control for ethnicity). There is a large literature which shows that wages are higher in unionized firms. Conditional on the type of employment contract, it is less plausible that workers' search activity depends on the unionization of the firm. Further, it is well known that previous employment situation has a strong effect on the wage, because it affects the bargaining position of the worker, but there is less reason to suspect that the previous employment status has a direct effect on the search position now (conditional on the type of contract). Finally, although it is standard that the wage depends on the type of occupation, there is less reason to believe that job search activity depends on a more detailed classification of occupational structure (conditional on contract type), so wage is
} 
one may imagine that individuals with low search costs (e.g. because of a well-developed personal network) are more likely to accept shorter employment contracts. ${ }^{24}$ As a consequence, the remaining employment duration is also endogenous. Note however that the observed remaining duration is predominantly a random draw from a duration distribution determined by the total employment duration and the probability that the employee leaves the job before the contract expires, so some of the variation in the remaining duration is purely exogenous. One of the consequences is that the potential bias of the remaining duration variable is substantially less than the potential bias of the total duration variables. This may imply that presuming exogeneity of the remaining duration is a reasonable assumption. Nevertheless, to deal with the potential bias we have investigated the endogeneity problem.

Taking into account the endogeneity of the contract duration is not standard, because the contract duration is related to the endogenously chosen type of contract. A permanent contract may be interpreted as a contract with a long remaining duration, of which the exact length is unknown. Therefore, we do not control for type of contract, but we instrument the observed contract duration of temporary workers and use the predicted contract duration of permanent workers using the same instruments. For workers with a permanent contract, we presume that the remaining contract duration is at least 5 years (and maximally 30 years), for the 'verbal contracts' and 'contracts of agreement', we presume that the contract duration is less than 5 years (and minimally one month). Hence, by means of interval regression we estimate the first stage of the instrumental approach, where DUR is measured in months:

$$
\log \left(D U R^{*}\right)=\gamma X_{1}+v_{1}, D U R^{*}=D U R \text { if } T E M P=1,
$$

instrumented with nine categories of occupation, whereas in the search model only manual and non-manual workers are distinguished. 


$$
\begin{gathered}
1 \leq D U R^{*} \leq 60 \text { if } T E M P=0 \text { for 'agreements' and verbal contracts, } \\
60 \leq D U R^{*} \leq 360 \text { for permanent employment contacts; }
\end{gathered}
$$

As instrument for the remaining duration we use whether the worker's firm is unionised, Estonian language skills and the two employment status indicators in the previous years. ${ }^{25}$ The results are reported in Table 5, specification [1]. We find now that the estimate of the coefficient of the (logarithm of the) remaining contract duration is substantially higher (in absolute value) and the MWP for the remaining contract duration is about twice as high. Note however that this estimate is not directly comparable to the MWP for the contract duration as reported in Table 4, because the latter estimate is conditional on the type of contract. Plausibly, as argued above, workers derive also utility from the type of contract (independent of the length of the contract). For example, workers with permanent contract are more likely to receive on-the-job training (Booth et al., 2002). Hence, the results reported in Table 5, specification [1] are consistent with those of Table 4, in the sense that they exceed those of Table 4 . We have also estimated the model instrumenting both the wage and the remaining contract duration using the same instruments as discussed above. Again the outcomes are rather insensitive to the choice of the instruments. It appears now that the MWP for an additional month is 7.4 (s.e. 3.5) ,so close to the standard probit estimate.

We have estimated the same models for males and females separately. A consistent finding for all the model specifications is that the estimate of the wage coefficient does not depend on gender, but the estimate for the coefficient of remaining duration is about 30 to 40

\footnotetext{
${ }^{24}$ Endogeneity does not occur when employers offer only one type of employment duration (e.g. one year). Because many employers tend to standardize the employment duration to fixed periods, the bias of the endogeneity maybe quite limited.

${ }^{25}$ As one may expect being unemployed or out of the labour force in previous year, have a strong negative effect on the (logarithm of the) contract duration, whereas workers in unionised firms have longer expected duration.
} 
percent lower for females. ${ }^{26}$ Hence, the estimates suggest that the MWP for the contract duration is (somewhat) higher for males than for females. This finding is in line with Booth et al. (2002), who report that males are more likely than females to experience a reduction in their future wages as a consequence of holding a temporary job.

Hence, our main conclusion is that workers attach substantial value to the remaining duration of their employment contract. Given the increased risk of becoming unemployed for workers with a temporary contract combined with the observations that only minority of unemployed in Estonia receive earnings-related unemployment benefits and that the unemployment rate was substantial (between 10 and 14 percent) at the period of observation, the above estimates seems intuitively reasonable. Different specifications imply about the same size for the value of a permanent job, whereas it is important to distinguish between estimates that are based on temporary workers and thus refer only to the absence of unemployment risk and estimates that are based on all workers and include other job attributes related to permanent contracts (e.g. more job training) as well. Note that we find that a worker is at least willing to pay once a monthly wage to swap a temporary contract into a permanent one. A formal stylised search model which leads to an estimate of similar order of magnitude is presented in section $5.3 .^{27}$

\footnotetext{
${ }^{26}$ Furthermore, all other coefficients of the explanatory variables except one (being divorced) have about the same value suggesting that for the Estonian labour market presuming that the coefficients are not gender specific is a reasonable assumption.

${ }^{27}$ Results reported in Tables 4 and 5 indicate that, other things equal, search effort declines with job tenure and increases with education.. Women are significantly less likely to search than men, other things equal. Night work is generally thought of as attribute that reduce utility. Our results however, do not suggest that night work has significant impact on search behaviour. Estimates by gender (not reported here) suggest that single men are less likely to search, while divorced women are more likely to search than those living with a partner. Males working
} 


\subsubsection{Lithuania}

The Lithuanian year 2000 data provide the total duration of employment contract and elapsed job tenure. Under the assumption that temporary contracts are not renewed, the remaining duration can be calculated as the total duration minus the job tenure. We include the logarithm of the total contract duration controlling for job tenure. The above assumption is probably valid for the majority of temporary workers as the contract duration is less than job tenure ( $76 \%$ of the temporary workers have a job tenure less than the contract duration). For the $24 \%$ of temporary workers who have a job tenure which exceeds the contract duration, it may still be the case that the total duration measure is a reasonable approximation of the remaining duration (controlling for tenure) ${ }^{28}$ This implies that our estimates of the MWP for remaining duration of the contract are somewhat downward biased for Lithuania, but because this bias only applies to the minority of workers it is likely very modest. Note that for Lithuania, the data do not distinguish between different types of permanent contracts. Table 6 (specifications [1] and [2]) provide estimates of a standard Probit model and a model with imputed contract duration of 10 years for permanent contracts. ${ }^{29}$ According to the latter, an average temporary worker (contract duration 6 months) is willing to pay 8 to 9 percent of monthly wage for a one month extension, or, equivalently, pay once about 150 (s.e. 36) percent of monthly wage to get a 10 year contract. These results (close to Estonian ones) hardly change when imputed duration for permanent contract is 5 rather than 10 years.

less than 55 hours a week and for females working less than 52 hours search activity decreases with working hours; above these limits search effort increases with hours.

${ }^{28}$ Given at random selection of working individuals, the expected remaining contract duration is exactly half the total contract duration for temporary workers (because the temporary contract duration is finite). So, the logarithm of the remaining duration is equal to the logarithm of the total duration plus random noise (under the assumption of random quitting behaviour).

29 We have repeated the estimates based on data for the period 2002-2003. Unfortunately, for this period, contract duration data were incorrectly reported and cannot be used in the current paper. However, for the model with temporary job dummy estimated coefficients were almost identical to the results for the year 2000 (the main 
As a sensivity analysis, we have re-estimated the model for Lithuania with the remaining contract duration calculated as the contract duration minus job tenure. For the minority of observations where the contract duration exceeds job tenure, we have calculated the remaining contract duration as half the total contract duration. It appears that the results are (almost) identical.

In one other specification (Table 6, specification [3]), we do not control for sector and region, but we control for the local unemployment rate (county and gender-specific) and the gender-specific annual percentage change in employment in the (two-digit) industry of respondent's main job; the latter is also interacted with the contract duration. It turns out that workers employed in a declining industry attach considerably higher values to occupying a permanent position: the willingness to pay for swapping a 6 months contract into a 10 years one goes up by 4.6 (s.e. 3.0) percent of monthly wage per each percentage point decline in industry employment. Presumably, in a declining industry the chances that a temporary job contract will be renewed or will be changed into a permanent position (within the same firm) are lower than in other industries. ${ }^{30}$ So, temporary workers are more concerned about an employment cut in the sector they work in. ${ }^{31}$ Further, the estimates by gender (not reported) indicate that the MWP to avoid temporary contracts is somewhat higher for men (178 percent of monthly wage, s.e. 54) than for women (118 percent of monthly wage, s.e. 43$)$.

About half of all workers work either at nights or on weekends (or both), and these job attributes prove to have an impact on search activities in Lithuania. Workers on average are

difference is that the statistical significance of most estimates is higher, due to a larger number of observations). This provides further support for our main result.

${ }^{30}$ See Booth et al. (2002) for evidence in Britain on the chances that a temporary job is changed into a permanent one within the same firm.

31 To the extent that a decline in industry employment can be interpreted as a job attribute, the estimates (Table 6, specification [3] suggest that a worker with a 6 month contract values each percentage point of (gender-and- 
willing to pay 4.5 percent (s.e. 1.7) of their monthly wage to avoid working an extra night and about 9.8 percent (s.e. 4.7) to avoid working an extra Saturday or Sunday (not at night). Reported estimates are based on proxies for proportion of nights and weekend days worked. These estimates suggest that the discomfort of working at night or in the weekends is substantial. Further, it indicates that the disutility of working during the weekend days is higher than during the night. This makes sense, as Lithuania is a (mostly) Catholic country, so working on weekends has the disadvantage of missing the Sunday service.

The effect of the local unemployment rate on the probability of being observed searching is theoretically ambiguous a priori: If the probability of finding a job is low, workers are expected to search less, however the period of search is increased as the probability of being accepted is small. Positive relationship between local unemployment and on-the-job search was recently documented for the UK by Fuentes (2002), but see Pissarides and Wadsworth (1994) and Mekkelholt (1993) for the Netherlands. We find that the local unemployment rate has a positive impact on workers' search effort. ${ }^{32}$

\subsection{A stylised search model}

We have seen above that the willingness to pay to avoid a temporary job exceeds the monthly wage. Hence, temporary workers are willing to pay once more than their monthly wage to obtain a permanent job. Does this make sense? We will use a stylised search model to show that estimates that imply that the willingness to pay to avoid temporary contracts exceeds the wage

industry-specific) fall in annual average employment at -6.3 (s.e. 3.2) percent of the monthly pay, while for a worker with a 5 years contract this MWP falls to -2 percent and becomes statistically insignificant.

${ }^{32}$ Finally, we will discuss the other determinants of the search decision. Results reported in Table 6 show that likelihood of search decreases with age and tenure (for tenures up to 21 years). Females and ethnic minorities are less likely to search, although both effects are not statistically significant. Like it was found for the UK by Pissarides and Wadsworth, 1994, tertiary education promotes on-the-job search. Divorced persons (like in Estonia) are more inclined to search. . 
rate are plausible. Suppose an individual has a temporary employment contract, earns wage $w$ and anticipates becoming unemployed at rate $\delta$ and finding a permanent job at rate $q$. The individual discounts the future at rate $\rho$. So, lifetime utility $V$ can be written as follows: $\rho V=w$ $+\delta(U-V)+q V^{p}$, where $\mathrm{V}^{\mathrm{p}}$ denotes the lifetime utility of a permanent contract. When unemployed, this individual will receive a benefit $B(B<w)$ with probability $\pi<1$ and will find again a temporary job at rate $\lambda$. In the permanent job, the individual will earn wage $w^{p}$ forever, so $\rho V^{p}=$ $w^{p}$. So, the unemployed lifetime utility $U$ can be written as: $\rho U=b+\lambda(V-U)$, where $b=\pi B$. Lifetime utility $V$ can then be written as:

$$
V=\frac{1}{\rho(\rho+\lambda+\delta)}\left(\frac{w+q V^{p}}{\rho+\lambda}+\delta b\right) .
$$

The willingness to pay (WP) for $\delta$ is defined as $[V(\delta)-V(0)] / \partial V / \partial w$, so:

$$
W P=-\frac{\delta}{\rho+\lambda}\left(w+q V^{p}\right)+\delta b(\rho+\lambda) .
$$

Now suppose that unemployment benefits levels are low, so $b=0$ (which will be a reasonable assumption for Lithuania and Estonia). It follows that:

$$
\frac{W P}{w}=-\frac{\delta}{\rho+\lambda}\left(1+\frac{q}{\rho} \frac{w^{p}}{w}\right) .
$$

For reasonably chosen values of the parameters, it appears that $W P / w<-1$. For example, data for Lithuania (OECD, 2003) indicate that $\lambda$, the annual rate of becoming re-employed, is 
0.35 and $\delta$, the annual rate of becoming unemployed for temporary workers, is at least 0.22 . Further, $q$ must be larger than $\rho$ and $w^{p}$ must exceed $w$. Presuming that the discount rate is 0.10 shows now that $W P / w$ is larger than one in absolute value, so the willingness to pay to escape a temporary job exceeds the current wage rate. ${ }^{33}$

\subsection{Hedonic wage estimates}

To compare the above estimates with an approach based on static compensating wage differentials, we have also estimated several hedonic wage models. These models include the same control variables as the search models plus the instruments discussed above. In line with other empirical studies, it appears that a hedonic wage model based on cross-section data gives a negative compensation estimate for a temporary job ${ }^{34}$ (see Moretti, 2000). Our estimates suggest that in Estonia workers with temporary contracts earn 14 percent less, other things equal; for men the differential is 16 percent, while for women just 9 percent Hedonic wage estimates for Lithuania are similar to Estonian: e.g. in 2000, temporary workers earned 8 percent less than then otherwise similar workers with permanent contracts. Hence, the conclusion, consistent with other hedonic wage studies, is that temporary workers are not compensated by higher wages which is generally perceived as a puzzle by most economists, but which may have an economic rationale. For example, Relitzer and Taylor (1991) use an efficiency wage model, assuming that monitoring of workers is costly and that product demand is uncertain, and show that wages paid to permanent workers exceed those paid to temporary workers. Note that because we do not have

\footnotetext{
${ }^{33}$ Likely, this simple model underestimates the true MWP, because we presume that workers are risk neutral, we ignore that temporary workers are more likely to leave the labor force and receive less on-the-job training.

${ }^{34}$ We find that there is a positive compensation differential for night work in Lithuania (this is in line with the literature, see Kostiuk (1990) and Lanfranchi et al. (2002), and consistent with the fact that the search method gives significant MWP to avoid night work in this country).
} 
a panel data set and unobserved heterogeneity related to productivity may bias these estimates, these hedonic wage results should be interpreted with caution. ${ }^{35}$

While we do not know whether a hedonic approach generates estimates that are in general better or worse than those based on job search activity/job mobility, as also argued by Gronberg and Reed (1994), we emphasise that the hedonic wage method presumes that workers are fully compensated and are perfectly mobile. It does not allow for the possibility that workers search for other jobs and that changes in jobs are not immediate (for example due to lack of information about other job alternatives). The absence of on-the-job search does not hold in our sample of temporary workers: $46 \%$ of workers with temporary contracts in our sample search for other jobs. So, the hedonic wage method presumes that workers are in jobs that maximise their utility, but in our sample, about half of the population of workers with temporary contracts are involved in on-the-job search and are therefore not in jobs that maximise utility. This indicates that the assumption of perfect mobility is not innocuous for research on the duration of the temporary employment contract. ${ }^{36}$

\section{CONCLUSION}

In this paper, we have demonstrated that the marginal willingness to pay for job attributes can be derived from data on on-the-job search activity. The main advantage of this estimation method, compared to estimation methods based on job moves, is that one needs less restrictive

\footnotetext{
${ }^{35}$ The inability to control for individual characteristics associated with higher probability of unemployment in a cross section may lead to a downward bias in the estimate of compensating differentials. In a cross section, workers of higher unmeasured ability may earn higher wages and suffer less unemployment, so that the observed differentials may be wrong-signed (Moretti, 2000).

${ }^{36}$ This raises the question whether our theoretical job search model is consistent with the observation that individuals accept temporary contracts when they know beforehand that they are not compensated? One answer consistent with search theory is that temporary contracts are mainly accepted by unemployed searchers (and job searchers with temporary contracts of shorter duration). By accepting a temporary job, unemployed searchers do not forego the opportunity to search for a permanent job. In equilibrium, these temporary jobs are more likely offered by
} 
assumptions on the search environment. In particular, one may assume that the workers' separation risk depends on nonwage job attributes such, as for example, the employment contract. The search approach to estimate the workers' marginal willingness to pay is applied to observations from Estonia and Lithuania. We have provided evidence that workers attach substantial value to the remaining duration of their employment contract and that the value of a permanent contract is higher in industries where employment falls.

less profitable firms, which have lower opportunity costs in having vacancies go unfilled, and which offer temporary jobs and lower wages (Hwang et al., 1992). 


\section{LITERATURE}

Altonji, J.G. and C.H. Paxson (1988), Labor supply preferences, hours constraints, and hours wage trade-offs, Journal of Labor Economics, 2, 254-276

Bartik, T.J., J.S. Butler and J.T. Liu (1992), Maximum score estimates of the determinants of residential mobility: Implications for the value of residential attachment and neighbourhood amenities, Journal of Urban Economics, 32, 233-256

Booth, A., M. Francesconi, and I. Frank (2002), Temporary jobs: stepping stones or dead ends?, Economic Journal, 112, 480, F189-F213

Brown, C. (1980), Equalizing differences in the labor market, Quarterly Journal of Economics, $113-134$

Carneiro, P., and J. Heckman (2002), The evidence on credit constraints in post-secondary Schooling, Economic Journal, 112, 482; 705-34

Carneiro, P, K.T. Hansen, and J. Heckman (2003), Estimating distributions of treatment effects with an application to the returns to schooling and measurement of the effects of uncertainty on college choice, International Economic Review, 44, 2; 361-422.

Eamets, R., and J. Masso (2004), Labour market flexibility and employment protection regulation in the Baltic States, IZA Discussion Paper No. 1147

Ekeland, Ivar, James J.Heckman, and Lars Nesheim (2003), Identification and Estimation of Hedonic Models, IZA Discussion Paper No.853.

EFILWC (2003a), European Foundation for the Improvement of Living and Working Conditions, Working Conditions in the Acceding and Candidate Countries

EFILWC (2003b), European Foundation for the Improvement of Living and Working Conditions, Working Time Preferences in sixteen European Countries

European Commission (2002), Employment in Europe 2002: Recent Trends and Prospects 
Fuentes (2002), On-the-job Search and the Beveridge Curve. IMF Working paper No. 02/37

Garen, J. (1988), Compensating wage differentials and the endogeneity of job riskiness, Review of Economics and Statistics, 70, 1, 9-16

Greene, W. H. (2000). Econometric analysis: Prentice Hall International

Gronberg, T.J. and W.R. Reed (1994), Estimating workers' marginal willingness to pay for job attributes using duration data, Journal of Human Resources, 24, 911-931

Hamermesh, D.S., W.H.J. Hassink and J.C. van Ours (1994), New facts about factor-demand dynamics: employment, jobs and workers, National Bureau of Economic Research, working paper No. 4625

Heckman, James J., Lance J. Lochner, and Petra Eyodd (2003), Fifty Years of Mincer Earnings Regressions, IZA Discussion Paper No. 775.

Heckman, J. (1974), Shadow prices, market wages and labor supply, Econometrica, 42, 679-694

Heckman, J., and X. Li (2003), Selection bias, comparative advantage and heterogeneous returns to education: evidence from China in 2000, IZA Discussion Paper No 829

Herzog, H. W. Jr. and A.M. Schlottmann (1990), Valuing risk in the workplace: market price, willingness to pay, and the optimal provision of safety, Review of Economics and Statistics, 72, 463-470

Hwang, H. D., W.R. Reed and C. Hubbard (1992), Compensating wage differentials and unobserved productivity, Journal of Political Economy, 100, 4, 835-858

Hwang, H. D., D.T. Mortensen and W.R. Reed (1998), Hedonic wages and labour market search, Journal of Labor Economics, 16, 4, 815-847

Kahn, L. and S. Low (1984), An empirical model of employed search, unemployment search and nonsearch, Journal of Human Resources, 19, 104-117

Khanker, R. (1988), Offer heterogeneity in a two state model of sequential search, Review of 
Economics and Statistics, 70, 2, 259-265

Kim, S. (1992), Search, hedonic prices and housing demand, Review of Economics and Statistics, $74,503-508$

Kostiuk, P.F. (1990), Compensating wage differentials for shift work, Journal of Political Economy, 98, 5, 1055-1075

Lanfranchi, J., H. Ohlsson and A. Shalli (2002), Compensating wage differentials and shift work preferences, Economic Letters, 74, 393-398

Maddala, G.S. (1983), Limited-dependent and qualitative variables in econometrics, Econometric Society Monographs

Manning, A. (2003), The real thin theory: monopsony in modern labour markets, Labour Economics, 10, 105-131

McCue, K. and W.R. Reed (1996), New evidence of workers' willingness to pay for job attributes, Southern Economic Journal, 62, 3, 627-652

Mekkelholt, E.W. (1993), Een sequentiele analyse van de baanmobiliteit in Nederland, PhD thesis, Amsterdam

Moretti, E. (2000), Do wages compensate for the risk of unemployment? Parametric and semiparametric evidence from seasonal jobs, Journal of Risk and Uncertainty, 20, 45-66

Mortensen, D.T. (1986), Job search and labor market analysis, in O.C. Ashenfelter and R. Layard (eds.), Handbook of Labor Economics, Amsterdam: North-Holland

OECD (2003), Labor markets and social policies in the Baltic Countries. Paris: OECD

OECD (2004). OECD Employment Outlook 2004. Paris: OECD

Pissarides, C.A. and J. Wadsworth (1994), On-the-job search: some empirical evidence from Britain, European Economic Review, 38, 385-401

Pissarides, C. A. (2000), Equilibrium Unemployment Theory, Cambridge: MIT Press 
Relitzer, J. B. and L. J. Taylor (1991), A model of dual labor markets when product demand is uncertain, Quarterly Jounal of Economics, 106, 4, 1374-1383

Rose, R. (2000). New Baltic Barometer IV: A survey study. Centre for the Study of Public Policy, Univ. of Strathclyde, Glasgow G1 1XH Scotland, 2000

Rosen, S. (1986), The theory of equalizing differences, in O.C. Ashenfelter and R. Layard (eds.), Handbook of Labor Economics, Amsterdam: North-Holland

Statistics Netherlands (1992), Enquête Beroepsbevolking 1992, CBS, Heerlen, the Netherlands

Van den Berg, G.J. (1990), Nonstationarity in job search theory, Review of Economic Studies, 5, 255-277

Van Ommeren, J.N., G.J. Van den Berg and C. Gorter (2000), Estimating the marginal willingness to pay for commuting, Journal of Regional Science, 40, 3, 541-563

Wooldridge, J. M. (2002), Econometric Analysis of Cross Section and Panel Data, MIT press, Cambridge, Massachusetts 
Table 1. Flows out of employment into unemployment and inelasticity by type of employment contract in Lithuania, 2000 and Estonia, 1998-1999 (percent)

\begin{tabular}{ccccccccc}
\hline & \multicolumn{4}{c}{ Estonia } & \multicolumn{4}{c}{ Lithuania } \\
& $1997-1998$ & $1999-2000$ & $1999-2000$ & $2002-2003$ \\
& Perm. & Temp. & Perm. & Temp. & Perm. & Temp. & Perm. & Temp. \\
Into Unemployment & 4.0 & 10.3 & 6.1 & 15.8 & 6.0 & 22.1 & 1.9 & 12.7 \\
Into Inactivity & 5.3 & 9.4 & 4.8 & 13.1 & & & 2.4 & 8.6 \\
\hline \multicolumn{4}{c}{ Notes: ${ }^{\text {a }}$ Source: LFS data and own calculation }
\end{tabular}

Table 2. Incidence of on-the-job search in Lithuania, 2000 and Estonia, 1998-2001

\begin{tabular}{|c|c|c|c|c|c|c|c|}
\hline \multirow{2}{*}{\multicolumn{2}{|c|}{ Employees }} & \multicolumn{3}{|c|}{ Lithuania } & \multicolumn{3}{|c|}{ Estonia } \\
\hline & & All & Men & Women & All & Men & Women \\
\hline All & & 8.8 & 9.6 & 8.1 & 4.2 & 4.8 & 3.7 \\
\hline Full-time & & 7.2 & 8.3 & 5.9 & 3.9 & 4.4 & 3.3 \\
\hline \multirow[t]{3}{*}{ of which: } & Tenure $\leq 6$ months & 13.9 & 14.4 & 13.1 & 6.5 & 7.5 & 5.4 \\
\hline & Tenure $2-5$ years & 7.3 & 8.5 & 5.9 & 4.0 & 4.2 & 3.9 \\
\hline & Tenure $\geq 15$ years & 2.9 & 2.8 & 3.0 & 1.3 & 1.3 & 1.3 \\
\hline \multirow{3}{*}{\multicolumn{2}{|c|}{$\begin{array}{l}\text { Part-time (less than } 32 \text { hours a week) } \\
\text { Working more than } 48 \text { hours a week } \\
\text { Temporary contracts }\end{array}$}} & 23.6 & 34.7 & 19.0 & 8.5 & 13.9 & 6.5 \\
\hline & & & & & 5.4 & 5.8 & 4.5 \\
\hline & & 45.5 & 53.1 & 32.6 & 26.8 & 30.3 & 21.3 \\
\hline \multirow{2}{*}{ Of which: } & $\leq 6$ months ${ }^{a}$ & 47.9 & 55.0 & 35.9 & 31.3 & 33.5 & 28.1 \\
\hline & $>6$ months ${ }^{\mathrm{b}}$ & 39.2 & 48.1 & 23.6 & 23.4 & 29.1 & 13.8 \\
\hline
\end{tabular}

Notes: ${ }^{a}$ For Estonia - contracts with remaining duration $\leq 3$ months. ${ }^{\mathrm{b}}$ For Estonia - contracts with remaining duration $>3$ months. Source: LFS data and own calculation.

Table 3. On-the-job search by reason in Lithuania, 2000 and Estonia, 2001

\begin{tabular}{|c|c|c|c|c|c|c|}
\hline & \multirow{4}{*}{\begin{tabular}{l}
\multicolumn{1}{c}{ Reasons } \\
Risk or certainty of loss of \\
present job / transitional job
\end{tabular}} & \multirow{2}{*}{\multicolumn{5}{|c|}{ Lithuanian employees }} \\
\hline \multirow[b]{3}{*}{1} & & & & & & \\
\hline & & All & Men & Women & Part-time & Temporary \\
\hline & & 19.3 & 21.5 & 17.0 & 17.0 & 64.7 \\
\hline 2 & Seeking more hours ${ }^{a}$ & 20.3 & 20.0 & 20.6 & 39.3 & 7.2 \\
\hline 3 & $\begin{array}{l}\text { Wish to have better working } \\
\text { conditions, pay etc. }\end{array}$ & 52.7 & 51.8 & 53.6 & 42.1 & 25.2 \\
\hline \multirow[t]{2}{*}{4} & Other & 7.8 & 6.8 & 8.8 & 1.6 & 2.9 \\
\hline & & \multicolumn{5}{|c|}{ Estonian employees } \\
\hline 1 & $\begin{array}{l}\text { Risk or certainty of loss of } \\
\text { present job / transitional job }\end{array}$ & 17.8 & 17.6 & 18.0 & 19.9 & 70.1 \\
\hline 2 & Seeking more hours & 21.5 & 20.5 & 22.8 & 31.6 & 8.9 \\
\hline 3 & $\begin{array}{l}\text { Wish to have better working } \\
\text { conditions, pay etc. }\end{array}$ & 57.9 & 58.2 & 57.5 & 46.2 & 21.0 \\
\hline 4 & Other & 2.8 & 3.6 & 1.9 & 2.3 & - \\
\hline
\end{tabular}


Table 4. Determinants of on-the-job search and MWP estimates for remaining temporary contract duration in Estonia (1998-2001)

\begin{tabular}{|c|c|c|c|c|}
\hline & \multicolumn{2}{|c|}{ [1] } & \multicolumn{2}{|c|}{ [2] } \\
\hline Method & \multicolumn{2}{|c|}{ Probit } & \multicolumn{2}{|c|}{ Two stage Probit ${ }^{a}$} \\
\hline Variables & Coeff. & s.e. & Coeff. & s.e. \\
\hline Log wage & $-0.406^{* * *}$ & 0.047 & $-0.637^{* * *}$ & 0.162 \\
\hline Log remaining contract duration ${ }^{b}$ & $-0.236^{* *}$ & 0.120 & $-0.241^{* *}$ & 0.117 \\
\hline Public service act & 0.314 & 0.226 & 0.317 & 0.224 \\
\hline Contract of agreement & 0.170 & 0.195 & 0.188 & 0.191 \\
\hline Verbal contract & $0.369^{* * *}$ & 0.124 & $0.331^{* * *}$ & 0.127 \\
\hline Temporary job & $1.231^{* * *}$ & 0.173 & $1.166^{* * *}$ & 0.171 \\
\hline Nights worked & 0.135 & 0.111 & 0.101 & 0.112 \\
\hline Weekly working hours & $-0.018^{* * *}$ & 0.007 & -0.010 & 0.010 \\
\hline Weekly working hours sq./100 & $0.019 * *$ & 0.008 & $0.016^{* *}$ & 0.009 \\
\hline Tenure & $-0.014^{* * *}$ & 0.005 & $-0.013^{* * *}$ & 0.005 \\
\hline Age & $0.064^{* * *}$ & 0.015 & $0.068^{* * *}$ & 0.015 \\
\hline Age squared/100 & $-0.098^{* * *}$ & 0.018 & $-0.105^{* * *}$ & 0.019 \\
\hline Rural resident & -0.062 & 0.061 & -0.047 & 0.061 \\
\hline Female & $-0.274^{* * *}$ & 0.056 & $-0.34^{* * *}$ & 0.065 \\
\hline Ethnic minority & -0.030 & 0.061 & -0.049 & 0.069 \\
\hline Single & -0.018 & 0.066 & -0.029 & 0.067 \\
\hline Divorced & $0.199 * * *$ & 0.073 & $0.198^{* * *}$ & 0.072 \\
\hline Higher education & $0.394^{* * *}$ & 0.108 & $0.485^{\star * *}$ & 0.124 \\
\hline Postsecondary prof. education & $0.194^{*}$ & 0.109 & $0.232^{*}$ & 0.110 \\
\hline Secondary general education & 0.104 & 0.086 & 0.124 & 0.085 \\
\hline Secondary vocational education & $0.190^{* *}$ & 0.089 & $0.214^{* *}$ & 0.089 \\
\hline Vocational education & 0.112 & 0.097 & 0.116 & 0.095 \\
\hline Non-manual occupation & -0.103 & 0.065 & -0.021 & 0.077 \\
\hline Plant size controls (5) & \multicolumn{2}{|c|}{ yes } & \multicolumn{2}{|c|}{ yes } \\
\hline Regional controls (16) & \multicolumn{2}{|c|}{ yes } & \multicolumn{2}{|c|}{ yes } \\
\hline Industry controls (15) & \multicolumn{2}{|c|}{ yes } & \multicolumn{2}{|c|}{ yes } \\
\hline Year dummies & \multicolumn{2}{|c|}{ yes } & \multicolumn{2}{|c|}{ yes } \\
\hline Pseudo R-squared & \multicolumn{2}{|c|}{0.1376} & \multicolumn{2}{|c|}{0.1216} \\
\hline $\log \mathrm{L}$ & \multicolumn{2}{|c|}{-3179.9} & \multicolumn{2}{|c|}{-3238.9} \\
\hline \multirow[t]{3}{*}{ Number of observations } & \multicolumn{2}{|c|}{21044} & \multicolumn{2}{|c|}{21044} \\
\hline & \multicolumn{4}{|c|}{ Derived MWP estimates ( $\%$ wage) } \\
\hline & \multicolumn{2}{|c|}{ [1] } & \multicolumn{2}{|c|}{ [2] } \\
\hline Job attributes & \multicolumn{2}{|l|}{ MWP } & MWP & s.e. \\
\hline $\begin{array}{l}\text { Remaining contract duration, } \\
\text { months }\end{array}$ & 9.7 & 5.1 & 6.3 & 3.5 \\
\hline Permanent ${ }^{\mathrm{d}}$ vs. 6 months contract & 170.9 & 89.3 & 130.1 & 72.2 \\
\hline
\end{tabular}

Notes: ${ }^{\mathrm{a}}$ In specification [2], the wage is instrumented. ${ }^{\mathrm{b}}$ Interacted with temporary job dummy. ${ }^{\mathrm{c}}$ For a worker with a new 6 months contract. ${ }^{\mathrm{d}}$ Assuming remaining duration 10 years.

${ }^{*},{ }^{* *},{ }^{* * *}$ - indicate that estimates are significantly different from zero at $0.01,0.05,0.10$ level respectively, based on robust standard errors. 
Table 5. Determinants of on-the-job search and MWP estimates for remaining contract duration in Estonia (1998-2001)

\begin{tabular}{|c|c|c|c|c|}
\hline \multirow[b]{3}{*}{ Variables } & \multicolumn{2}{|c|}{ [1] } & \multicolumn{2}{|c|}{$[2]$} \\
\hline & \multicolumn{2}{|c|}{ Two-stage probit ${ }^{a}$} & \multicolumn{2}{|c|}{ Two-stage probit ${ }^{b}$} \\
\hline & Coeff. & s. e. & Coeff. & s. e. \\
\hline Log wage & $-0416^{* * *}$ & 0.047 & $-0.838^{* * *}$ & 0.168 \\
\hline Log remaining contract duration & $-0.517^{* * *}$ & 0.115 & $-0.372^{* * *}$ & 0.129 \\
\hline Nights worked & 0.101 & 0.112 & 0.065 & 0.113 \\
\hline Weekly working hours & $-0.025^{* * *}$ & 0.007 & -0.008 & 0.010 \\
\hline Weekly working hours sq./100 & $0.026^{* * *}$ & 0.008 & $0.017^{*}$ & 0.009 \\
\hline Tenure & $-0.013^{* * *}$ & 0.005 & $-0.010^{* *}$ & 0.005 \\
\hline Age & $0.066^{* * *}$ & 0.015 & $0.073^{* * *}$ & 0.015 \\
\hline Age squared/100 & $-0.101^{* * *}$ & 0.018 & $-0.111^{* * *}$ & 0.019 \\
\hline Rural resident & $-0.084^{* *}$ & 0.060 & -0.066 & 0.060 \\
\hline Female & $-0.274^{* * *}$ & 0.054 & $-0.403^{* * *}$ & 0.065 \\
\hline Ethnic minority & -0.040 & 0.061 & -0.084 & 0.069 \\
\hline Single & -0.046 & 0.067 & -0.057 & 0.067 \\
\hline Divorced & $0.177^{* *}$ & 0.072 & $0.184^{* * *}$ & 0.071 \\
\hline Higher education & $0.411^{* * *}$ & 0.110 & $0.553^{* * *}$ & 0.118 \\
\hline Postsecondary prof. education & $0.219^{* *}$ & 0.109 & $0.272^{* *}$ & 0.108 \\
\hline Secondary general education & 0.114 & 0.087 & $0.139^{*}$ & 0.084 \\
\hline Secondary vocational education & $0.200^{* *}$ & 0.090 & $0.229^{* * *}$ & 0.088 \\
\hline Vocational education & 0112 & 0.089 & 0.111 & 0.095 \\
\hline Non-manual occupation & -0.098 & 0.064 & 0.041 & 0.078 \\
\hline Plant size controls (5) & \multicolumn{2}{|c|}{ yes } & \multicolumn{2}{|c|}{ yes } \\
\hline Regional controls (16) & \multicolumn{2}{|c|}{ yes } & \multicolumn{2}{|c|}{ yes } \\
\hline Industry controls (15) & \multicolumn{2}{|c|}{ yes } & \multicolumn{2}{|c|}{ yes } \\
\hline Year dummies & \multicolumn{2}{|c|}{ yes } & \multicolumn{2}{|c|}{ yes } \\
\hline Pseudo R-squared & \multicolumn{2}{|c|}{0.1227} & \multicolumn{2}{|c|}{0.1086} \\
\hline $\log \mathrm{L}$ & \multicolumn{2}{|c|}{-3245.7} & \multicolumn{2}{|c|}{-3298.1} \\
\hline \multirow[t]{3}{*}{ Number of observations } & \multicolumn{2}{|c|}{21075} & \multicolumn{2}{|c|}{21075} \\
\hline & \multicolumn{4}{|c|}{ Derived MWP estimates (\% wage) } \\
\hline & \multicolumn{2}{|c|}{$[1]$} & \multicolumn{2}{|c|}{$[2]$} \\
\hline Job attributes & MWP & s.e. & MWP & s.e. \\
\hline $\begin{array}{l}\text { Remaining contract duration, } \\
\text { months }\end{array}$ & 20.7 & 5.3 & 7.4 & 3.5 \\
\hline Permanent vs. 6 months contract & 427.7 & 109.3 & 152.6 & 72.1 \\
\hline
\end{tabular}

Notes: ${ }^{\text {a }}$ The remaining contract duration is instrumented for all workers (temporary and permanent workers), see (8a)-(8c), while the wage is not instrumented

b. The wage is instrumented. The remaining contract duration is instrumented for all workers (temporary and permanent workers).

${ }^{\mathrm{c}}$ For a worker with a new 6 months contract.

${ }^{*},{ }^{* *},{ }^{* *}$ - indicate that estimates are significantly different from zero at $0.01,0.05,0.10$ level respectively, based on robust standard errors. 
Table 6. Determinants of on-the-job search and MWP estimates for contract duration in Lithuania, 2000.

\begin{tabular}{|c|c|c|c|c|c|c|}
\hline \multirow[t]{2}{*}{ Variables } & \multicolumn{2}{|c|}{ [1] } & \multicolumn{2}{|c|}{ [2] } & \multicolumn{2}{|c|}{ [3] } \\
\hline & Coeff. & s.e. & Coeff. & s.e. & Coeff. & s.e. \\
\hline Log wage & $-0.639 * * *$ & 0.111 & $-0.635^{* * *}$ & 0.111 & $-0.570^{* * *}$ & 0.105 \\
\hline Temporary job $^{\mathrm{a}}$ & $1.421^{* * *}$ & 0.309 & & & & \\
\hline Log contract duration $^{\mathrm{a}}$ & -0.236 & 0.165 & $-0.316^{* * *}$ & 0.049 & $-0.286^{* * *}$ & 0.049 \\
\hline Night work & $0.564^{* * *}$ & 0.189 & $0.568^{* * *}$ & 0.188 & $0.453^{* *}$ & 0.185 \\
\hline Weekends & $0.491^{* *}$ & 0.224 & $0.497^{* *}$ & 0.223 & $0.518^{* *}$ & 0.225 \\
\hline Weekly working hours & $-0.050^{* * *}$ & 0.017 & $-0.050^{* * *}$ & 0.017 & $-0.057^{* * *}$ & 0.016 \\
\hline Weekly working hours sq. /100 & $0.048^{* *}$ & 0.020 & $0.048^{* *}$ & 0.020 & $0.055^{* * *}$ & 0.019 \\
\hline Tenure & $-0.026^{*}$ & 0.015 & $-0.026^{*}$ & 0.015 & $-0.031^{* *}$ & 0.015 \\
\hline Tenure sq. /100 & 0.065 & 0.042 & 0.066 & 0.042 & $0.077^{*}$ & 0.042 \\
\hline Age & $-0.018^{* * *}$ & 0.005 & $-0.018^{* * *}$ & 0.005 & $-0.016^{* * *}$ & 0.004 \\
\hline Rural resident & $-0.257^{*}$ & 0.134 & $-0.253^{*}$ & 0.134 & $-0.397^{* * *}$ & 0.126 \\
\hline Female & -0.165 & 0.109 & -0.166 & 0.109 & -0.030 & 0.114 \\
\hline Ethnic minority & -0.162 & 0.134 & -0.162 & 0.134 & -0.037 & 0.124 \\
\hline Single & $-0.224^{*}$ & 0.117 & $-0.221^{*}$ & 0.117 & -0.163 & 0.116 \\
\hline Divorced & $0.278^{*}$ & 0.150 & $0.279^{*}$ & 0.150 & $0.285^{*}$ & 0.146 \\
\hline Higher education & $0.605^{* * *}$ & 0.208 & $0.607^{* * *}$ & 0.209 & $0.521^{* *}$ & 0.204 \\
\hline Secondary education & 0.311 & 0.201 & 0.315 & 0.202 & 0.232 & 0.196 \\
\hline Vocational education & $0.426^{*}$ & 0.251 & $0.437^{*}$ & 0.252 & 0.326 & 0.251 \\
\hline Non-manual occupation & -0.049 & 0.129 & -0.049 & 0.129 & -0.017 & 0.128 \\
\hline Empl. growth sector ${ }^{b}, \%$ & & & & & $-0.041^{*}$ & 0.025 \\
\hline (Empl. growth sector $\times$ Log dur.)/10 & & & & & 0.088 & 0.055 \\
\hline Local unemployment rate $^{\mathrm{c}}, \%$ & & & & & $0.039^{* * *}$ & 0.013 \\
\hline Plant size controls (4) & \multicolumn{2}{|c|}{ yes } & \multicolumn{2}{|c|}{ yes } & \multicolumn{2}{|c|}{ yes } \\
\hline Regional controls (12) & \multicolumn{2}{|c|}{ yes } & \multicolumn{2}{|c|}{ yes } & \multicolumn{2}{|c|}{ no } \\
\hline Industry controls (24) & \multicolumn{2}{|c|}{ yes } & \multicolumn{2}{|c|}{ yes } & \multicolumn{2}{|c|}{ no } \\
\hline Pseudo R-squared & \multicolumn{2}{|c|}{0.2159} & \multicolumn{2}{|c|}{0.2157} & \multicolumn{2}{|c|}{0.1978} \\
\hline $\log \mathrm{L}$ & \multicolumn{2}{|c|}{-581.6} & \multicolumn{2}{|c|}{-581.7} & \multicolumn{2}{|c|}{-595.0} \\
\hline
\end{tabular}

\section{Derived MWP estimates (\% wage)}

\begin{tabular}{lcccccc}
\hline Job attributes & {$[\mathbf{1}]$} & & {$[\mathbf{2}]$} & \multicolumn{1}{c}{$[\mathbf{3}]$} & \\
\hline & MWP & s.e. & MWP & s.e. & MWP & s.e. \\
Contract duration, months ${ }^{\mathrm{d}}$ & 6.3 & 4.6 & 8.4 & 2.0 & 9.1 & 2.3 \\
Permanent vs. 6 months contract & 131 & 98 & 149 & 36 & 160 & 40 \\
\hline
\end{tabular}

Notes: Probit estimates with robust standard errors, 2641 observations. ${ }^{a}$ Duration of permanent contract is assumed to be 10 years in specifications [2] and [3]. ${ }^{\mathrm{b}}$ Gender-specific percentage of employment growth by 15 major NACE sectors. ${ }^{c}$ Gender-specific unemployment rate (percent) according to November 1999 LFS in the county where respondent's main job is located. ${ }^{\mathrm{d}}$ For a worker with a 6 months contract.

${ }^{*},{ }^{* *},{ }^{* * *}$ - indicate that estimates are significantly different from zero at $0.01,0.05,0.10$ level respectively, based on robust standard errors. 